\title{
Fabrication of Continuously Porous Alumina Body by Fibrous Monolithic and Sintering Process
}

\author{
Taek-Soo Kim ${ }^{1}$, In-Cheol Kang ${ }^{1}$, Takashi Goto ${ }^{2}$ and Byong-Taek Lee ${ }^{1, *}$ \\ ${ }^{1}$ Chungnam Research Center for Nano Materials and School of Advanced Materials Engineering, Kongju National University, \\ 182 Shinkwan-dong, Kongju, Chungnam 314-701, Korea \\ ${ }^{2}$ Institute for Material, Research, Tohoku University, Sendai, Japan
}

\begin{abstract}
A continuously porous alumina sintered body was successfully fabricated using by the fibrous monolithic process, in which carbon and flour were used as a pore forming agent. An equation was driven for anticipating the microstructural change during extrusion as a function of the extrusion ratio, and it was identified that the resultant microstructure obtained from using the fibrous monolithic process agreed well with the calculated size using the equation. The third passed and sintered alumina body includes continuous pores of about $42.5 \mu \mathrm{m}$ in diameter at an intended direction, while the second one consists of $228 \mu \mathrm{m}$. Fine pores were also found to form along the alumina surfaces with $0.1-10 \mu \mathrm{m}$ in diameter. There was no shape change during binder burning out and sintering processes.
\end{abstract}

(Received June 13, 2003; Accepted July 30, 2003)

Keywords: porous alumna, fibrous monolithic process, microstucture

\section{Introduction}

Porous ceramics with pores of about $3 \mathrm{~nm}-15 \mu \mathrm{m}$ in diameter have been developed for environmental use such as filters, membranes, etc. ${ }^{1)}$ The typical candidates are some inorganics such as $\mathrm{Al}_{2} \mathrm{O}_{3}, \mathrm{ZrO}_{2}, \mathrm{TiO}_{2}$ and $\mathrm{SiO}_{2}$, corresponding to their chemical, thermal and physical stabilities. Those are fabricated by processes such as hot pressing, ${ }^{2,3)}$ sintering, ${ }^{4,5)}$ extrusion ${ }^{6,7)}$ and slip-casting ${ }^{8)}$ etc. However, development of porous ceramics has been progressing in spite of the numerous necessities and interests. This is because the porous materials for industrial use should have not only appropriately high porosity and uniform size of the pores, but also mechanical strength. Simultaneous retention of the strength and porosity suitable for the environmental application is hard to obtain because if porosity increases, the strength becomes lower, or vice versa. In addition, pore size and distribution is not easy to control. Thus, an efficient process needs to be developed for fabricating the porous ceramics, having porosity, strength and various pore sizes.

To date, the fibrous monolithic process was introduced to fabricate a toughened ceramic body successfully by controlling the microstructure. ${ }^{9,10)}$ It is defined as a repeated extrusion of two or more ceramic powders combined by organic binders according to the principle that the area of each extruded bar is homogeneously reduced with the extrusion ratio. However, research on the fabrication of a continuously porous ceramic body has not yet been conducted by using the fibrous monolithic process.

In this study, a continuously porous $\mathrm{Al}_{2} \mathrm{O}_{3}$ body was fabricated by using the fibrous monolithic process. Size, distribution and morphology variation of the continuous pores were investigated as functions of pore forming agents such as carbon and flour, as well as passes of extrusion using electron microscopy such as a scanning electron microscope (SEM) and a high resolution transmission electron microscope (HRTEM). Both agents are known to be effective pore

*Corresponding author, E-mail: lbt@kongju.ac.kr forming agent without deteriorating the mechanical properties. $^{11)}$

\section{Experimental Procedures}

Homogenous mixtures of commercially used alumina/ polymer and carbon (or flour)/polymer were prepared using a heated blender (C. W. Brabender Instruments, Inc., PL2000 Plasti-Corder with Roller Blade Mixing Heads). The average diameter of the starting materials were about $0.3 \mu \mathrm{m}$ for alumina (AKP-50, Sumimoto, Japan), 10-15 $\mu \mathrm{m}$ for carbon powder (SMC, Korea.) and 20-30 $\mu \mathrm{m}$ for flour (Gompyo, Daehan flour Corporation, Korea). The polymer used for the binder in the shape of granules (Elvax 250, Dupont) was composed of Ethylene Vinyl Acetate (EVA). Detailed properties of the constituents are listed in Table 1. Stearic acid $\left(\mathrm{CH}_{3}\left(\mathrm{CH}_{2}\right)_{16} \mathrm{COOH}\right.$, Daejung Chemicals \& Metals Vo., Ltd, Korea) was also added for lubrication during blending. The ratio of each constituent in the mixture was 50/45/ 5 vol\% for the alumina/polymer/lubricant and 55/40/ $5 \mathrm{vol} \%$ for the graphite powder or flour powder/polymer/ lubricant.

In order to blend both the alumina and pore materials with the polymer, the polymer granules were first put into the mixing chamber and head which were heated to $403-433 \mathrm{k}$ using an oil type heating source. Then, the alumina powder or the pore materials was added slowly to the chamber having the heated head revolving at $60 \mathrm{~min}^{-1}$. The three mixtures of $\mathrm{Al}_{2} \mathrm{O}_{3}$ /polymer, graphite/polymer and flour/polymer were respectively extruded at $383 \mathrm{~K}$ into a filament $3.5 \mathrm{~mm}$ in diameter with an extrusion ratio of $73.5: 1$. Then, the alumina and carbon (or flour) filament were reloaded in the extrusion die as densely as possible and reextruded under an extrusion ratio of $61: 1$. This process was continued till the third passed filaments were obtained. Binder burn-out (BBO) of the filaments was carried out at $973 \mathrm{~K}$ under flowing argon and sintered at $1723 \mathrm{~K}$.

The microstructure of the filaments was examined using a Field Emission Scanning Electron Microscope (FE-SEM, 
Table 1 Typical properties of the constituents used for this investigation.

\begin{tabular}{llcl}
\hline & \multicolumn{1}{c}{ Usage } & $\begin{array}{c}\text { Density } \\
\left(D / \mathrm{Mg} \mathrm{m}^{-3}\right)\end{array}$ & Composition \\
\hline Alumina & Matrix & 3.98 & $\alpha$-alumina \\
\hline Carbon & Porosity former & 2.26 & Activated carbon \\
\hline Flour & Porosity former & & 2323 \\
\hline Elvax 250 & Binder & 0.951 & $\begin{array}{l}\text { Ethylene- } \\
25 \% \text { Vinyl acetate }\end{array}$ \\
\hline
\end{tabular}

JSM 6335F), Transmission Electron Microscope (TEM, EM2010) and Energy Dispersed Spectroscopy (EDS, Oxford 400), respectively. For TEM observation, the sintered body was cut into a disc $3 \mathrm{~mm}$ in diameter using a diamond cutter (Struers Minitom), dimple ground (Gatan Model656) and ion-milled (Pips, Gatan). The structure of the resultant phases was characterized by an X-ray diffractometer (Rigaku, AX2500) using $\mathrm{Cu} \mathrm{K} \alpha$ of $0.1542 \mathrm{~nm}$.

\section{Results}

Figure 1 shows SEM microstructure of the fibrous monolithic filaments of the alumina/polymer and carbon/ polymer composite bars after the second ( $a$ and $d)$, third (b and e) and fourth (c and f) extrusion. Here, the Figs. 1(a), 1(b) and $1(\mathrm{c})$ were taken from the longitudinal direction of the extrusion, while Figs. 1(d), 1(e) and 1(f) from the transverse direction. The second filaments show an alternate distribution of the both alumina/polymer (bright color) and carbon/ polymer (dark color) layers, in which thickness of the carbon layer is about $450 \mu \mathrm{m}$. As the number of extrusion increases, the thickness becomes thinner, being about $60 \mu \mathrm{m}$ for the third filament. Because of the resolution limit, the microstructure in the fourth filament (Fig. 1(c) and (f)) was too fine to observe. The irregular pattern of both layers formed along the extrusion direction is possibly attributed to difficulty sectioning the soft polymer phases.

Figure 2 showed SEM microstructure of the fibrous monolithic alumina/flour filaments after the first to third extrusion, in which (a)-(c) are taken from a longitudinal direction, while (d)-(f) are from a transverse. Flour was used as a substitute for the carbon. The flour was reported as a good pore-forming agent like the carbon. ${ }^{11)}$ It can be seen that the pore materials are well distributed and surrounded by alumina/polymer along the extrusion direction as in the case of the carbon. The diameter of the flour/polymer layer (dark color) is about $1.73 \mathrm{~mm}$, as can be seen in Figs. 2(a) and (d), but became about $228 \mu \mathrm{m}$ after the second extrusion (Figs. 2(b) and (e)) with increasing the number of layers to 34 . The filaments after the third passes (Figs. 2(c) and (f)) present a finer microstructure than those after the second pass, which is also unable to distinguish the size of the layers with the same magnification.

In order to control the pore shape and specific surface area during the fibrous monolithic process, each carbon/polymer filament was arranged within the extrusion die as shown in Fig. 3(a) and then extruded. The resultant microstructure from the first to third extrusion is as shown in Figs. 3(b), (c)
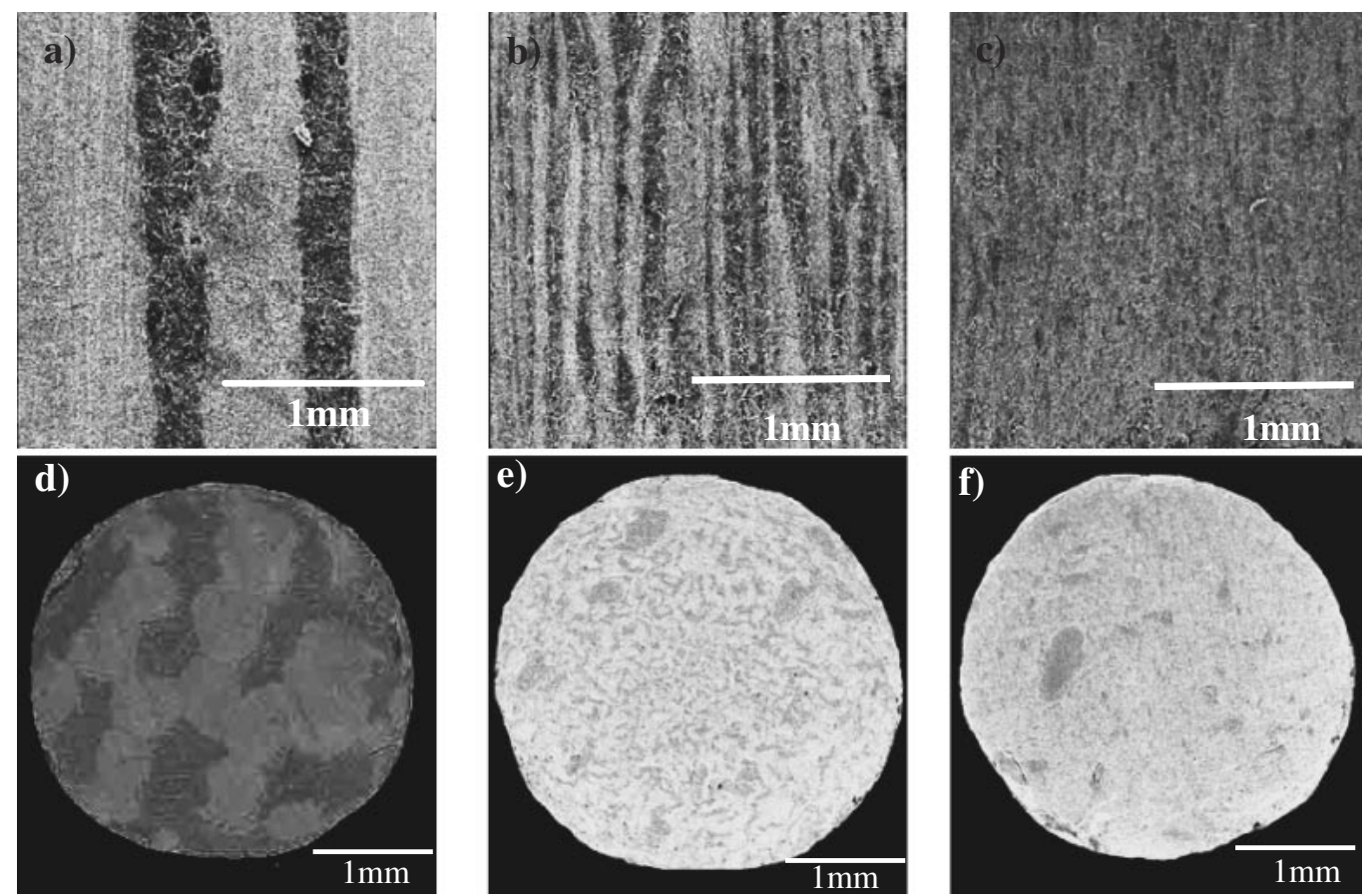

Fig. 1 SEM micrographs of fibrous monolithic alumina/polymer-carbon/polymer filaments with passes of extrusion (a and d: 2nd pass, b and e: 3rd pass, c and f: 4th pass). 

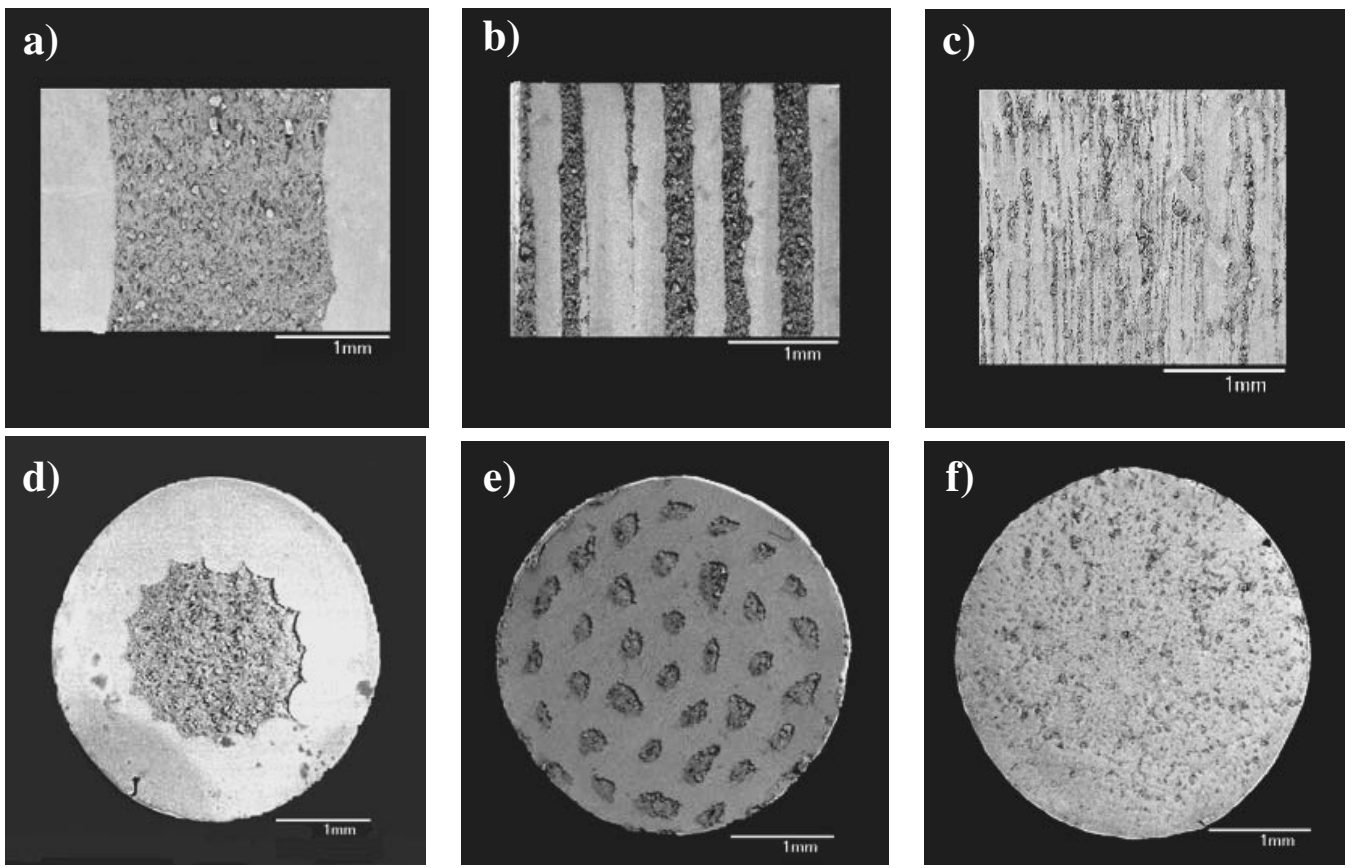

Fig. 2 SEM micrographs of fibrous monolithic alumina/polymer-flour/polymer filaments with passes of extrusion, showing circular shape (a and d: 1st pass, b and e: 2nd pass, c and f: 3rd pass).
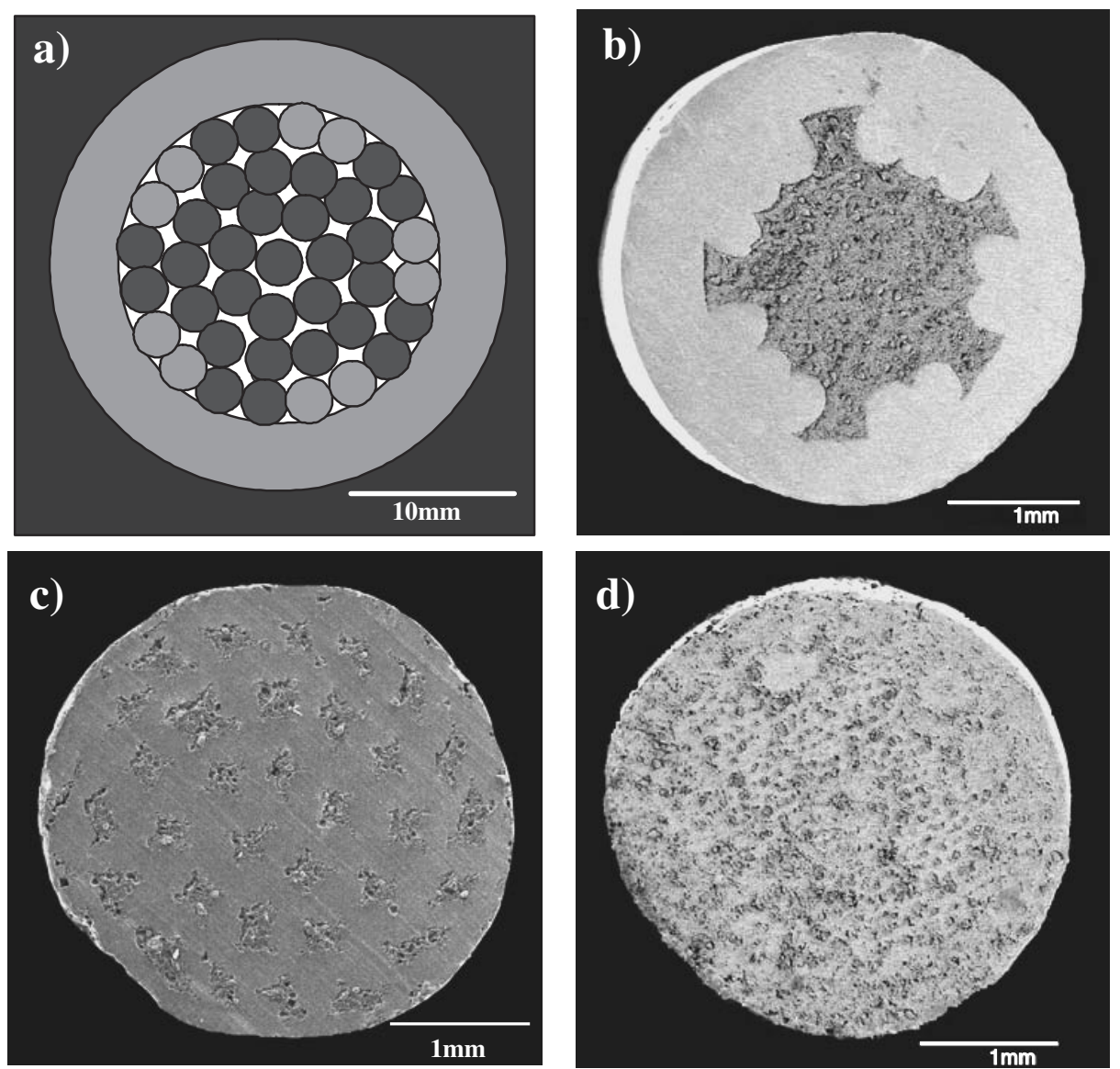

Fig. 3 Schematic for designing pore (a) and SEM micrographs of fibrous monolithic alumina/polymer-flour/polymer filaments from the first (b) to second (c) and third passes of extrusion (d), showing astral shape. 

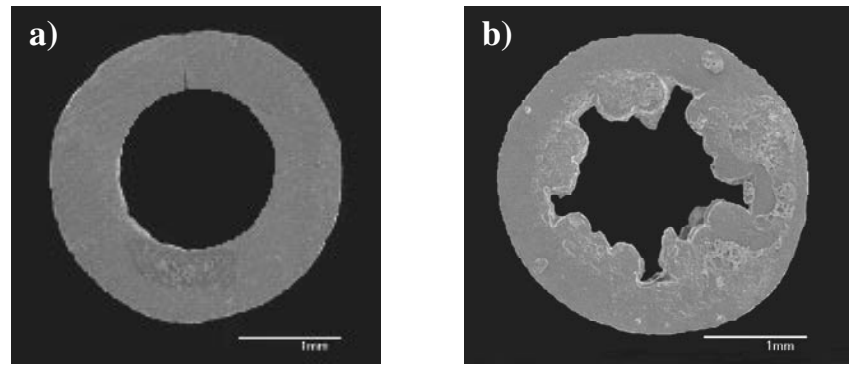

Fig. 4 SEM microstructure of the first passed and sintered alumina body carbon powder (a) and flour (b).

and (d). The shape of the pore materials was different from those shown in Fig. 2, but the size became refined as the extrusion passes $(b-d)$ increased. To sum up, the fibrous monolithic process seems to be an easy and effective way to control the ceramic microstructure and pore shape as intended. Figures 4(a) and (b) show a continuous pore formed in the alumina body by the binder burning-out and sintering processes. This indicates that the binder and pore forming agents such as carbon and flour were successfully removed during the both processes. The pores still maintained their circular (Fig. 4(a)) and astral shapes (Fig. 4(b)) as designed. The only variation is the reduction of about $17 \%$ in volume, which is generally understood to occur during sintering. Figure 5 shows the SEM microstructure taken from the central (b) and surface parts (c) of the sintered alumina frame, where the surface meets the continuous pore. The irregular shape of the sintered body (Fig. 5(a)) is due to an arbitrary fracture by the author. It is seen that the alumina frame has a dense structure, whereas the surface contains various pores in both size and shape, being $1-10 \mu \mathrm{m}$ in diameter. The average grain size in the frame is about $300 \mathrm{~nm}$ in diameter, which is similar to that of the starting material (Fig. 5(b)). No reaction substance was found to form in the sintered body during the binder burning-out and sintering processes as shown in Fig. 6. The XRD traces taken from the alumina/polymer and carbon/polymer, respectively, detected alumina and carbon particles distributed in the amorphous phase binder. A carbon peak was detected from the burnedout alumina/polymer-carbon/polymer filament, but disappeared after the second binder burning-out process.

Figure 7 shows a TEM bright field image taken from a
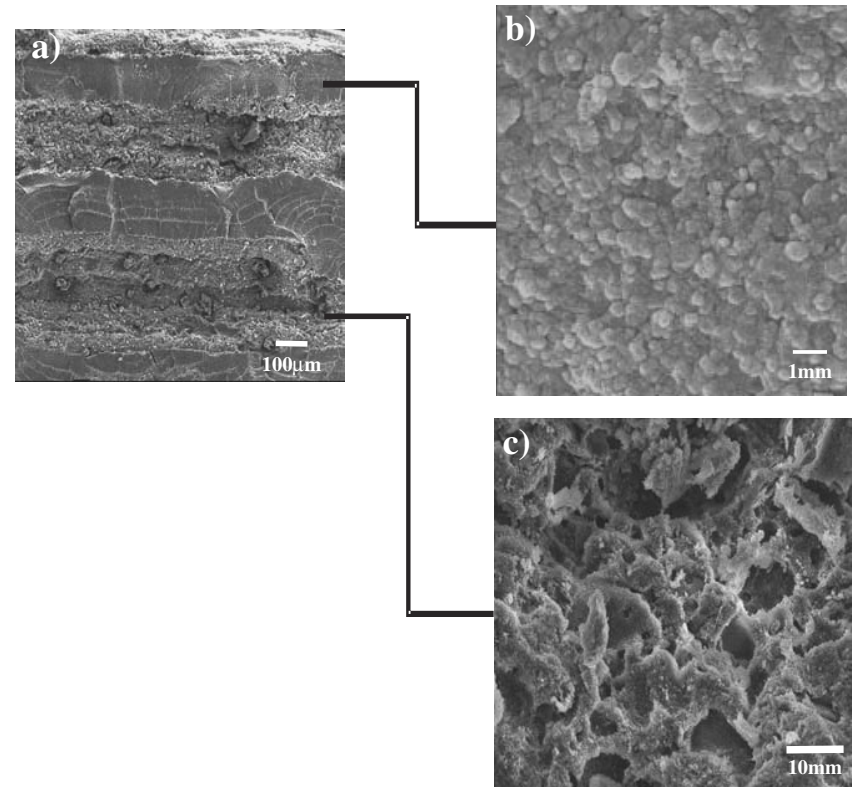

Fig. 5 SEM microstructure of the second passed and sintered fibrous monolithic alumina filament (a), its enlarged pictures taken from the alumina frame (b) and the surface (c).

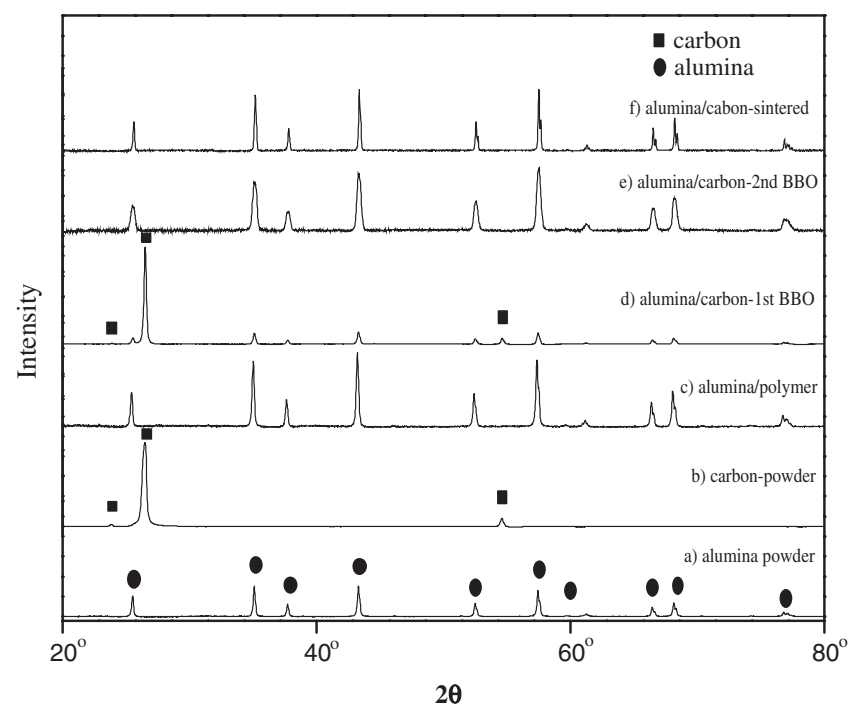

Fig. 6 XRD profiles of the alumina/polymer-carbon/polymer composites with each process.
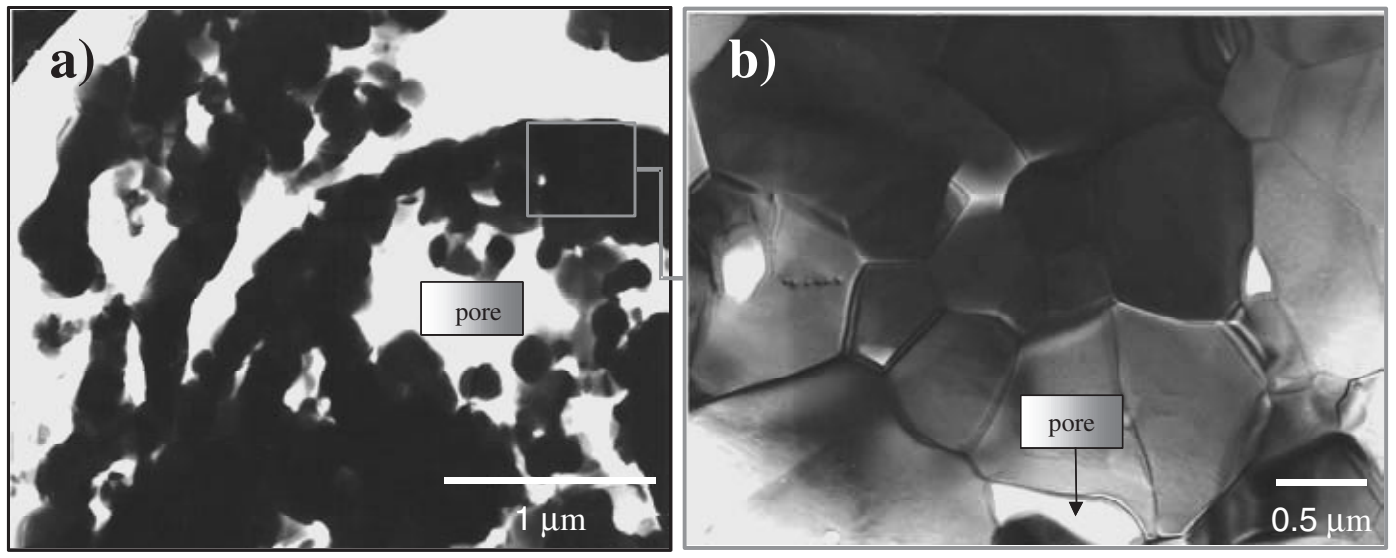

Fig. 7 TEM bright field image of the third passed and sintered porous alumina body (a) and its enlarged image (b). 
porous alumina sintered body, in which the dark and white areas (a) point up the alumina frame and second pore, respectively. An enlarged image of the alumina frame (b) presents grains of about $0.6 \mu \mathrm{m}$ and some pores of about $0.1-$ $0.4 \mu \mathrm{m}$ formed by incomplete sintering.

\section{Discussion}

Extrusion is one of the best known working processes to make a product dense, hard and homogeneous in shape. The resultant properties of the extruded materials usually depend on some necessary factors such as die and billet temperature, ram speed, area reduction (extrusion) ratio, die geometry etc. The fibrous monolithic process used in this work is regarded as a kind of extrusion process and focuses on controlling the reduction ratio among the factors. Continuous extrusion makes the resultant microstructure fine as much as the extrusion ratio or reduction ratio allows. The microstructural refinement which accomplishes during extrusion can be calculated corresponding to the following equation,

$$
r_{n}=r_{n-1} / R^{1 / 2}
$$

where, $R$ is reduction ratio and $r_{n}$ is the resultant radius of the extruded filament after $n$ pass. The equation indicates that the thickness of the extruded bar is refined depending on the reduction ratio.

According to the equation, the diameter of the extruded bar varies from $3.5 \mathrm{~mm}$ after the first extrusion to $448 \mu \mathrm{m}$ after the second, $57.4 \mu \mathrm{m}$ after the third and finally $7.3 \mu \mathrm{m}$, whereas the diameter of pore materials changes from $14.2 \mathrm{~mm}$ to $3.5 \mu \mathrm{m}$ after the fourth extrusion, as listed in Table 2. The reduction ratio was about $74: 1$ until the first extrusion, but became $63: 1$ from the second extrusion, due to the reduction in the area of feed rods. The initial diameters of the feed rod and the pore materials were $30 \mathrm{~mm}$ and $21 \mathrm{~mm}$, respectively.

The comparison of the microstructural change between the calculated and measured is as listed in Table 2. The first extruded filament contains continuous pore layers of about $1.73 \mathrm{~mm}$ in diameter under the same extrusion ratio with the calculation. Further extrusion resulted in a homogenous reduction in the diameter, being $228.0 \mu \mathrm{m}$ for the second pass and $42.5 \mu \mathrm{m}$ for the third pass. Both measured and calculated values are well within a discrepancy of less than 7 percent. The large mismatch of about 55\% obtained from the third filament may be attributed to factors as follows; (1) Similar size between the anticipated pore diameter and the raw flour. The mean diameter of the flour $(20-30 \mu \mathrm{m})$ is almost the same as the expected pore size of $27.4 \mu \mathrm{m}$ after the third extrusion, resulting in insufficient flowability during the

Table 2 Size variation of the pore and rod of the extruded filament with passes.

\begin{tabular}{ccccccc}
\hline \multicolumn{2}{c}{ Reduction ratio } & \multicolumn{2}{c}{$73.5 \%$} & \multicolumn{3}{c}{$61 \%$} \\
\hline The number of extrusion & Initial & 1st pass & 2nd pass & 3rd pass & 4th pass \\
\hline Rod diameter & $30 \mathrm{~mm}$ & $3.5 \mathrm{~mm}$ & $448 \mu \mathrm{m}$ & $57.4 \mu \mathrm{m}$ & $7.3 \mu \mathrm{m}$ \\
\hline \multirow{2}{*}{$\begin{array}{c}\text { Pore } \\
\text { diameter }\end{array}$} & Calculated & $14.2 \mathrm{~mm}$ & $1.70 \mathrm{~mm}$ & $214 \mu \mathrm{m}$ & $27.4 \mu \mathrm{m}$ & $3.5 \mu \mathrm{m}$ \\
\cline { 2 - 7 } & Measured & $14.2 \mathrm{~mm}$ & $1.73 \mathrm{~mm}$ & $228 \mu \mathrm{m}$ & $42.5 \mu \mathrm{m}$ & - \\
\hline
\end{tabular}

extrusion. (2) Relatively large size mismatch between the pore materials being $20-30 \mu \mathrm{m}$ and alumina less than $300 \mathrm{~nm}$. Thus, it is recommended that a similar size between the ceramic and the pore material should be used. (3) Difference in the plastic flow rate between alumina/polymer and flour/ polymer layers during extrusion, due to the existence of different ceramics. (4) Large elastic modulus of the polymer rather than that of ceramic. The ceramic and polymer compound might be expanded in volume at exit of the die during extrusion.

It is important that the controlled microstructure is maintained even after sintering. The fibrous monolithic process is one of the most efficient ways of designing microstructure of hard materials like ceramics by combining them with soft materials like polymers. Once the microstructure is successfully achieved as intended by using the fibrous monolithic process, the binder burning-out process has to follow to remove the binder, because the role of the polymer is only to make the ceramics flow during extrusion rather than to improve the resultant property. It takes a long time, being careful, due to the relatively large volume ratio of polymer in the composite. The binder consists of polyethylene of $72 \%$ and vinyl acetate of $28 \%$ with a density of $0.951 \mathrm{Mg} / \mathrm{m}^{3}$. Hrdina et al. ${ }^{12)}$ reported that the process for binder removal is very complicated and that care is required. Vinyl acetate begins to resolve into acetic acid at $543 \mathrm{~K}$, and then the acetic acid fully removed at $643 \mathrm{~K}$. Polyethylene, the other type of the binder, resolves between $673 \mathrm{~K}$ and $773 \mathrm{~K}$. This work continues until the binder becomes fully separated by repetition of the decomposition and phase transformation during the binder burning-out process. Thus, a rapid and incomplete reaction may induce a change in the dimensions of the sintered body as well as a deterioration of the sinter ability.

Figures 4(a) and (b) indicate that both the binder burningout and sintering processes do not alter the shape of the fibrous monolithic alumina body, but successfully form continuous pores. The XRD profile of the porous alumina sintered body reveals that carbon did not remain but only alumina (Fig. 6). It is known that carbon used as a porous alumina gives rise to a reaction during sintering as follows; ${ }^{4}$

$$
\begin{aligned}
& 2\left\langle\mathrm{C}_{\text {solid }}\right\rangle+\left\{\mathrm{O}_{2, \text { gas }}\right\} \leftrightarrow 2\left\{\mathrm{CO}_{\text {gas }}\right\} \\
& \left\langle\mathrm{Al}_{2} \mathrm{O}_{3, \text { solid }}\right\rangle+2\left\langle\mathrm{C}_{\text {solid }}\right\rangle \leftrightarrow\left\{\mathrm{Al}_{2} \mathrm{O}_{\text {gas }}\right\}+2\left\{\mathrm{CO}_{\text {gas }}\right\}
\end{aligned}
$$

Thus, the gaseous products would form enclosed pores during the sintering, as well as result in weight loss. Full removal of the carbon as well as the polymer during the binder burning-out at relatively lower temperature of about $973 \mathrm{~K}$ than that of sintering will cause reaction (1) rather than (2). The XRD characterization indicated that the polymer was successfully decomposed and yielded elemental carbon during the binder burning-out under nitrogen atmosphere (Fig. 6(d)), and the carbons newly formed and used for the pore forming agent were fully removed during the post burning out process.

Formation of the fine pores less than $10 \mu \mathrm{m}$ in diameter along the surface of the alumina frame (Fig. 5) enhances the surface area for reaction, and then becomes more effective for environmental use. In addition, fine distribution of the 
alumina grains less than $1 \mu \mathrm{m}$ in diameter will effectively resist to the fracture of the porous materials. The increase of the porosity as well as fracture toughness by controlling the microstructure will extend the application area even to the human body.

\section{Conclusion}

A continuously porous alumina sintered body was fabricated by using fibrous monolithic process and its microstructural change was examined. Refinement of the microstructure in the alumina frame and pore size occurred during extrusion can be anticipated by the newly established formula; $r_{n}=r_{n-1} / R^{1 / 2}$, where, $R$ is reduction ratio and $r_{n}$ is the resultant radius of the $n$ passed filament. The equation agreed well with the real measurement. Besides the size, the shape of the pores was controlled by the fibrous monolithic process. Binder burning-out and sintering processes removed the binder and gave rise to the formation of a continuously porous alumina body with various sizes and shaped pores as designed. Fine pores from 0.1 to $10 \mu \mathrm{m}$ in diameter were formed along the surface of the alumina frame, and then enhanced the surface area.

\section{Acknowledgement}

This work was supported by the 2002 NRL research program of Korean Ministry of Science and Technology.

\section{REFERENCES}

1) K. Ishizaki, S. Kormarneni and M. Nanko: Porous Materials (Vol. 4) in Materials Technology Series, (Kluwer Academic Publishing, Boston Hardbound, 1998) pp. 181-190.

2) V. Biasini, M. Parasporo and A. Bellosi: Thin Solid Films 297 (1997) 207-211.

3) M. Nanko, K. Ishizaki and T. Fujiawa: J. Am. Ceram. Soc. 77 (1994) 2437-2442.

4) K. Maca, P. Dobsak and A. R. Boccaccini: Ceramics International 27 (2001) 577-584.

5) S. T. Oh, K.-I. Tajima, Motohide Ando and T. Ohji: Mater. Lett. 48 (2001) 215-218.

6) R. A. Terpstra, B. C. Bonekamp and H. J. Veringa: Desalination 70 (1988) 395-404.

7) H. T. Wang, X. Q. Liu, Y. Zhou, D. K. Peng and G. Y. Meng: Membrane Technol. 171 (1997) 47-51.

8) A. J. Burggraaf and K. Keizer: Synthesis of inorganic membranes: In: R. R. Rhave, Editor, Inorganic Membranes: Synthesis, Characteristics and Applications (1991) pp. 23-27.

9) S. Y. Lienard, D. Kovar, R. J. Moon, K. J. Bowman and J. W. Halloran: J. Mater. Sci. 35 (2000) 3365-3371.

10) G. H. Kim, T. S. Kim and B. T. Lee: Korean J. Mater. Research 13 (2003) 213-218.

11) G. A. Merkel and M. J. Murtagh: Unites State Patent 5,258,150 (1993).

12) K. E. Hrdina and J. W. Halloran: J. Mater. Sci. 33 (1998) 2805-2815. 